\title{
Quality marketing: Making marketing more strategic
}

\begin{abstract}
Laura Patterson
is a 25-plus-year marketing and sales veteran having worked for both large public companies such as State Farm and Motorola as well as start-ups. In her career, she has only worked for two types of people, engineers and accountants. Both care deeply about data and numbers, and so her passion for metrics was really based on career survival. In 1999 she cofounded VisionEdge Marketing (www.visionedgemarketing.com), a data-driven metrics-based strategic and product marketing company that specializes in improving marketing performance and helping organizations create a competitive advantage designed to attract, secure and retain profitable customers. Author of dozens of published marketing and branding articles and the books Gone Fishin' and Measure What Matters, Laura has served on several nonprofit boards, provided programming for professional organizations such as the ANA and BMA, and has served as a guest lecturer at various universities, including the University of Texas at Austin, Stanford University and Purdue University. Laura earned her BA from Truman State University and her Master's at the University of South Florida.
\end{abstract}

Keywords: marketing, budget, performance measurement, metrics, brand management, market share

Abstract In various studies over the course of the past year, accountability has surfaced as one of the top issues in marketers' minds today. From the Association of National Advertisers, to Frost \& Sullivan, to IDC and to the CMO Council, marketing accountability has been front and center at conferences and in papers. The reason is that CEOs are demanding more accountability from marketing.

Journal of Digital Asset Management (2007) 3, 71-78. doi:10.1057/palgrave.dam.3650072

\section{INTRODUCTION}

While most marketers are measuring something, survey results indicate that there is room for improvement regarding metrics and the quality of these metrics. Many companies are investing more resources, both people and money, into marketing performance measurement. IDC's study, "Planning Your 2006 Marketing Budget" released in September, indicated that over the next 12 months, 38 per cent of the 95 companies are participating in the study plan to deploy measurement processes. This undertaking will require new skills and capabilities that explain why 12 per cent of these companies plan to launch new marketing operations teams or roles to address marketing performance management. Earlier in 2005, Elana Anderson, a principal analyst at Forrester Research, said, "Marketing must improve its value to justify its existence as a centralized function." If we do not make our case and develop and communicate quality metrics, we may find the days of marketing as a stand-alone department numbered and instead find ourselves absorbed into sales, finance or some other function.

It is not like this is a new phenomenon. The concept of measuring marketing has been around for a long time. The question is what are metrics and how to measure them. In 2001, James Gregory's paper in the Journal of Brand Management shared a proprietary model that linked various financial factors and corporate images to stock prices, sales and market share. Our own research at VisionEdge Marketing ${ }^{1}$ has found that most companies fail to measure such things as cost to acquire, order value, share of wallet, churn rate or brand equity and key business variables' marketing impacts. Rather, they measure such things as response rate, demo participation, event traffic, number of new contacts or leads, number of press hits, cost per lead and lead aging. While these metrics offer some insight into the results of specific programs, they do not link marketing to the business objectives. In fact, our studies indicate that only about one in four marketers measure marketing's impact on the business, and nearly two-thirds of marketing plans do not even include metrics.

\section{A METRICS FRAMEWORK}

Forrester Research, Marketing Management Analytics and the Association of National Advertisers $^{2}$ conducted an online survey in the 
first half of 2005 to find out how marketing professionals leverage marketing analytics. Fifty per cent of the respondents indicated that measurement remains the hardest part of marketing, and 51 per cent are dissatisfied with how they measure marketing return on investment (ROI). Yet nearly all of the respondents realize that measuring marketing is important and impacts senior management's confidence in the marketing personnel and programs.

To make progress on the marketing measurement front, marketing professionals must shift from tactically based metrics to metrics that are linked more to business outcomes. The measures must include both financial and nonfinancial goals. The figure below illustrates the continuum of marketing metrics and how marketing metrics are evolving (Figure 1).

Starting at the bottom-left and working up and to the right, we can use this illustration as a framework to explore how marketing metrics are evolving from tactical to strategic. Activitybased metrics refer to those things we can count. This was marketing's first foray into the world of measuring - looking for things we could count, such as press hits, click through rates, CPMs (cost per thousand) and so on. Most marketing plans today consist of activity lists such as the number of ads to run, the number of tradeshows to attend, the number of new product brochures to produce, the number of research studies to conduct and so on. Marketing then reports on the status of these activities, sometimes in very creative ways such as red to indicate incomplete or in jeopardy and green to communicate completion or on track. These are then turned into charts in an attempt to present the marketing dashboard. Yet with activity-based metrics, all we have is a colorful status report and no information on the impact of these activities on the business. The company cannot make any key business decisions or determine whether the strategies are working.

Operational metrics, the next level, is a step forward. These metrics focus on improving the efficiency of the organization. Typical metrics in this stage include cost-per-lead, lead aging, leads-per-sales rep and campaign ROI . The goal is to squeeze out any inefficiency. While this is a noble pursuit and an important one, marketing efficiency alone will not make a company successful. What really "moves the needle" in terms of business performance is how well its marketing identifies product opportunities, positions these products, builds market traction against the competition and fosters customer loyalty. Performance outweighs efficiency.

Once we accomplish a systematic approach to outcome-based metrics, we will have the basis for advancing to Leading Indicator Metrics, those metrics that help us determine the likelihood of a particular outcome and eventually creative models to use metrics to predict outcomes. And once we have mastered Leading Indicator Metrics, we are only a few financial models away from Predictive Metrics, those that allow us to predict a business outcome.

Both activity-based and operational metrics are a good place to start, but neither serves as an accurate indicator of strategic effectiveness.

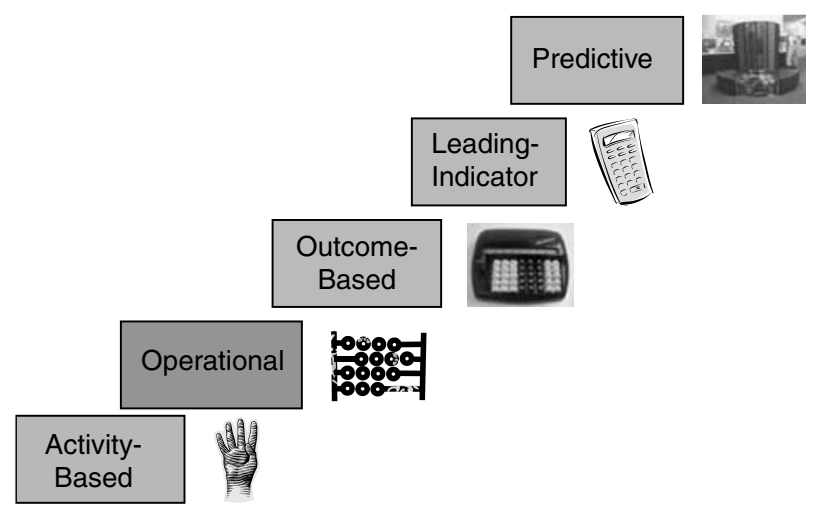

Figure 1: The metrics continuum: from tactical to strategic 
Neither enables the organization to determine which efforts are having the greatest impact, provide a quality control process, focus on marketing's contribution to the company's overall valuation or serve as a good way to demonstrate marketing's accountability. To address these, marketing executives and professionals need to evolve outcome-based metrics to develop quality measures. Outcomebased metrics focus on three specific business outcomes: market share, lifetime value (LTV) and brand equity.

\section{THE ROLE OF MARKETING IN BUSINESS OUTCOMES}

In his book, Kotler on Marketing (1999), Phil Kotler" claimed that "Marketing has the main responsibility for achieving profitable revenue growth for the company (p. 18)." We do this by finding, keeping and growing profitable customers. Finding, keeping and growing profitable customers form the basis of marketing's role: customer acquisition, customer penetration and growing customer value. Each of these can be squarely aligned with three specific business outcomes as illustrated in the next figure: market share, LTV and brand equity.

What company does not want to see each of these continue to improve over time? Every company wants to be a dominant player in its market however that market is defined. Every company wants to retain its customers and increase its LTV. Ultimately, every company, whether private or public, wants to increase its shareholder value. This depends on high brand equity. The higher the brand equity, the greater the shareholder value (Figure 2).

These three roles - market share, LTV and brand equity - become the gauges that marketing monitors. Marketing objectives and strategies are deployed to move the needle on each gauge. The more effective the strategies and the better they are executed, the more positive will be the impact the marketing can have on improving each outcome.

\section{MOVING THE NEEDLE}

These are the business outcomes that marketing should address. Now, the question becomes how we move the needle of each gauge. That is, what variables do we need to affect that will impact each outcome. For each outcome, there is a specific set of variables.

\section{Market share}

Market share is generally defined as the company's share of total sales of all the products within the category in which the company's brand/products compete. The share number is derived by dividing your company's product/

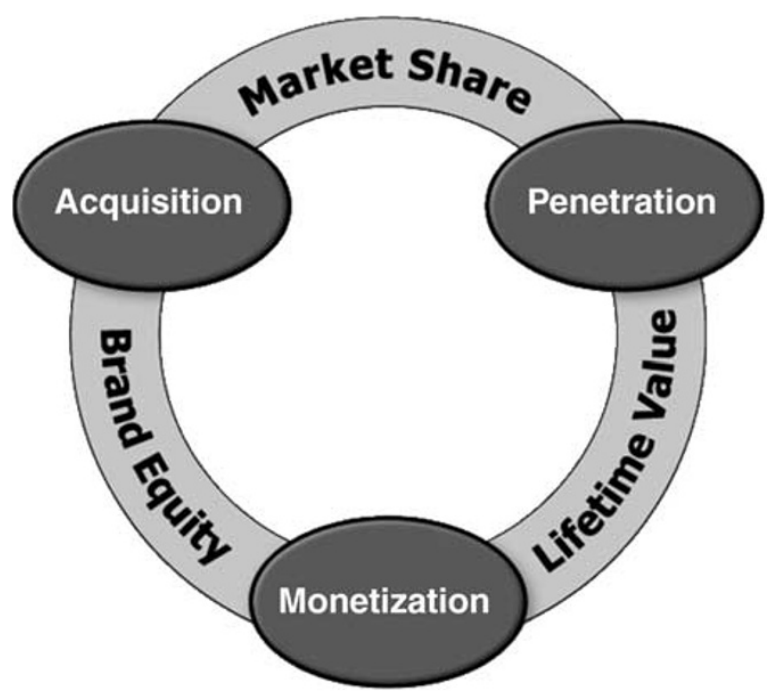

Figure 2: Marketing's link to business outcomes 
brand sales volume by the total category sales volume.

$$
\text { MS }=\frac{\text { Brand Sales Volume }}{\text { Total Category Sales }}
$$

Indicators that your company is gaining a share over the competition include the following variables:

1. First, more and more potential customers must be made aware of your offer. You must own a share of voice, which is the relative frequency, weight and quality of your communication compared to the competition and clutter.

2. Once potential customers are aware of you, they must put you on the short list of consideration. You must have some share of preference, the second variable to monitor.

3. Increasing the extent to which your channel partners recommend and sell your products versus competitive alternatives - this is known as share of distribution - the third variable. Two other variables are important factors.

4. The rate at which you attract and acquire new customers.

5. The rate of your growth compared to the growth of the category.

The actual number of customers you acquire as well as the rate of acquisition are key factors. While you may be able to have consideration, if the customer does not select you, you cannot gain a share. You now have five quality measures. Strategies and tactics that positively impact these variables will ultimately affect your market share.

\section{Lifetime value}

Acquiring a customer is just the start. The next key business outcome is to keep this customer and grow its value. Each customer is worth something and, typically, the longer you keep the customer, the more that individual customer is worth. Most companies know how long they need to keep the customer to recoup the cost to initially acquire that one customer. LTV is a powerful metric and a meaningful business outcome. If your company is merely a revolving door for customers, your profitability will suffer. LTV is the net profit each customer contributes to the business over its entire life time as a customer. Research suggests that companies with higher LTV customers spend less money on servicing customers, can increase their prices more easily and can enjoy more referrals (a lower cost of acquisition).

The simplest LTV calculation (there are several) is total revenue received from the customer while a customer minus the costs of providing that customer with products/services. You will need to include costs of goods sold, selling costs and support costs. Using the average cost per unit, while sufficient for calculating overall LTV, can be deceiving if using LTV for customer segmentation purposes because the selling costs and support costs vary dramatically by customer.

Sidebar - A defected One way to get to customer who comes customer service cost is to back after the average take the number of units life time number should be treated as a new customer, sold annually and divide it by the annual customer service cost and to have otherwise all customers a number for each unit. will have "infinite" You can do the same lifetimes, and you lose thing for returns, support, the relevance of the metric. invoicing, etc and eventually come up with a total cost per unit.

Growing LTV is the ultimate indicator of a good return on marketing. In fact, return on marketing investment (ROMI) can be calculated by subtracting the last year's LTV from the current year's LTV and dividing the sum by the current year's marketing investment.

\section{ROMI - LTV current year - LTV previous year Marketing Investment}

Four variables will help move the LTV gauge.

1. Tenure. The longer a customer is a customer, the more likely they will continue to be a customer.

2. Frequency. The more frequently they purchase, the greater the likelihood their LTV will grow. 
3. Share of wallet. This is your share of the customer's budget allocated for your types of products/services that you secure. It is a valuable way to measure your ability to compete if the customer is spending more of their allocated budget on products and services from your company as opposed to spreading their dollars around.

4. Advocacy. The more likely they are to continue to buy products from you, that is, the greater their loyalty, which is the final quality measure.

Perhaps, a few examples will help illustrate this concept. It is one thing for a customer to consistently buy the same brand of dishwashing soap, printer paper, medical device or test equipment again and again. This is purchase frequency. But let us say your company has several products, that is, you make and sell dishwashing soap, paper towels, toilet paper, shampoo, toothpaste and so on. Most households buy a variety of these products. The company captures a greater share of this customer's wallet when more of these products are purchased by the buyer from the same company. The concept applies to any company whether they make medical devices, provide financial services or sell software and services.

The last variable is loyalty. If it is one thing to have a satisfied customer, it is another to have a loyal customer - a customer who is very unlikely to switch and is highly likely to refer. Again, when marketing focuses on strategies and tactics that improve these measures, they will ultimately move the LTV needle.

\section{Brand equity}

We can now discuss the last marketing metric and business outcome, brand equity. At this point, we are successfully acquiring customers and keeping them. There are numerous complicated ways to measure brand equity. We would like to suggest something simpler that drives home the contribution that marketing makes. Brand equity is the sum of the value of your customer franchise times your price premium. Therefore, the greater the value of your customer franchise, which is the aggregate value of purchases from all of your customers who repeatedly buy your brand, and the more you can command for your product/service relative to competing offers within your category, the higher your company's brand equity.

Brand Equity $=$ Customer Franchise value $\star$ Price

In addition to these two quality measures, three other variables impact brand equity. The rate at which new products are accepted, your product's profit margin compared to the profit margin in the category and your overall net advocacy score. The advantage of a strong loyal customer base is that these customers are often the first to adopt your newest products and services, thereby improving the rate of new product adoption, which impacts the time to generate revenue for a new product. Existing customers give your new offer reference ability and momentum. Existing customers are more likely to adopt a new product quicker and will help pave the way for entry into adjacent markets.

\section{Sidebar - creating a market strategy}

If you are unfamiliar with developing a market strategy, a classic approach is to use the Ansoff matrix (Figure 3). The matrix serves as a good strategic planning tool and also helps support the idea of leveraging existing customers to enhance product adoption. Essentially, Ansoff suggests that there are four primary strategies:

1. Market Penetration - done by selling more current products to existing markets by raising the retention rate, by increasing customer spend or by winning competitors' customers. This is basically repeating what you are doing today.

2. Product Development - bringing new products to existing customers and markets. The company is leveraging its existing base.

3. Market Development - taking current products to new markets. This is taking proven products to customers and markets that are not familiar with you, which are therefore harder than just bringing a new product to an existing customer who hopefully has a positive disposition to your company and its offers. 


\begin{tabular}{|c|c|c|}
\hline & Present Product & New Product \\
\hline $\begin{array}{c}\text { Present } \\
\text { Market }\end{array}$ & $\begin{array}{c}\text { Market } \\
\text { Penetration }\end{array}$ & $\begin{array}{c}\text { Product } \\
\text { Development }\end{array}$ \\
\hline $\begin{array}{c}\text { New } \\
\text { Market }\end{array}$ & $\begin{array}{c}\text { Market } \\
\text { Development }\end{array}$ & Diversification \\
\hline
\end{tabular}

Figure 3: Adapted from Igor Ansoff's book, Implanting Strategic Management (1990)

4. Diversification - involves both new products developed and brought to new markets. This is the hardest strategy.

With these quality measures, every marketing professional and executive can be both accountable and at the same time impact the company's strategic direction. By measuring and monitoring these factors and keeping an eye on the gauges, marketing professionals and marketing executives can begin to understand whether strategies are having an impact and how well tactics are being executed. And, more importantly, we can take a seat at the executive table and participate in a meaningful discussion about the business rather than a tactical discussion about trade show logistics, ad placements and email conversion rates. While these activities are important and still need to be monitored, they would not get us a seat at the executive table. And while focusing on these quality measures and key metrics would not stop the CFO from asking questions about ROI and costs, it will help change the dialogue to one that is about the impact of marketing programs as a whole on the business.

\section{CREATING YOUR DASHBOARD}

Marketing performance management and metrics tracking would be incomplete without a way to capture and report the metrics, that is, a dashboard. Ideally, metrics indicate the business health of your organization. A dashboard is the visual representation of a firm's health and provides a snapshot between actual performance and the goals. A good dashboard facilitates action. It not only reports on the metrics being monitored but also serves as a vehicle to help decide on what actions are required and their priorities. Yet, according to the June 2005 study conducted by CMO Magazine, ${ }^{4}$ three-fourths of marketers have no formal scorecard.

Creating a dashboard is more than just producing a few charts and graphs. A dashboard is a visual and diagnostic vehicle that communicates marketing's effectiveness and impact on business goals. Every metric provides a specific perspective on the firm's business. Some metrics indicate whether there is a problem today, and others help alert marketing to a potential problem down the road. The status of the marketing organization on the metrics continuum will impact what kind of dashboard it can create. As business goals change, it will be important to revisit the dashboard to make sure that the dashboard metrics are still in alignment with the business needs and goals.

As companies progress along the metrics continuum from activity- to outcome-based, the dashboard will also evolve. Outcome-based metrics involve a dashboard that hones in on the primary business outcomes we have discussed: market share, customer penetration and customer value. Because these metrics tend to be more market-centric, the dashboard begins to provide more strategic insight and direction.

The greatest challenge for the marketing organization is how to capture the metrics. Manual aggregation of data across multiple spreadsheets comes with potential issues ranging from error-prone reporting and poor utilization of internal resources. Moving from a spreadsheet-based system to an automated system provides greater benefits to the organization as a whole.

But you need not invest huge resources in new systems to create dashboards. A basic set of charts such as those depicted below will serve the purpose. While it may perhaps be a bit more time consuming, this approach will help you really understand your measures and your business.

Here is a fictitious example (Figure 4) of a dashboard using some of the metrics we have discussed. In this example, these five charts paint an alarming picture. The company may be closing lots of deals, but might not be aware 
of the precipitous cliff facing them if they did not know that their repeat orders and net advocacy or dropping off and that their market value index and wins compared to the competition are concerning. The fact that they are experiencing a sharp decline in their prices suggest that their differentiation and therefore their brand strategy is no longer effective. This information can help them ask important questions and make key business decisions.

\section{MEASURE WHAT MATTERS}

We began this discussion about the need for marketing to be more accountable and to develop quality metrics. Hopefully, as a result of this paper/presentation, you have some new ideas on how to focus marketing metrics around business outcomes and how to develop quality metrics that will help you provide insight into how marketing is making a contribution to the company - and how to demonstrate that contribution to senior management. So in

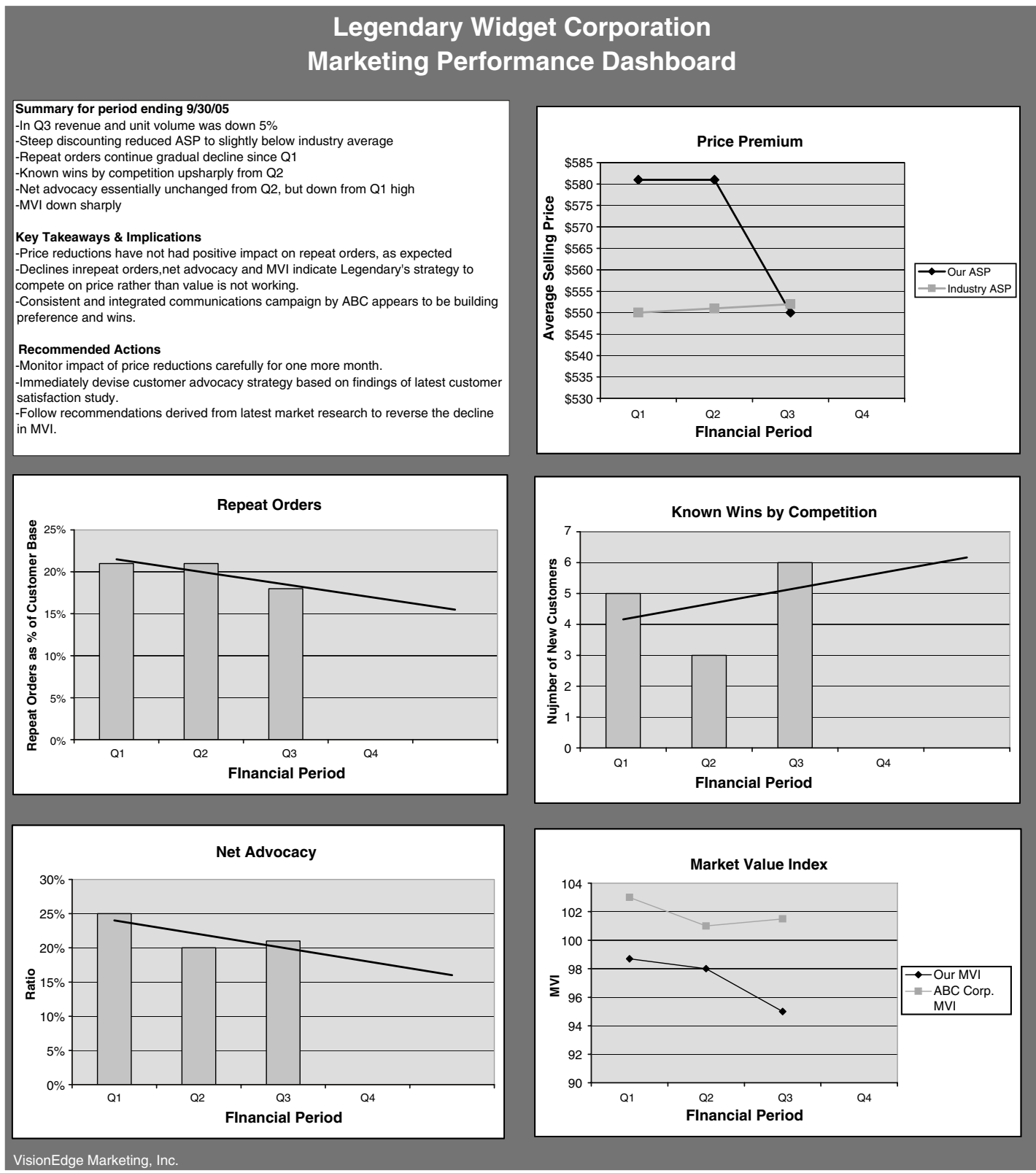

Figure 4: Fictitious dashboard example 
closing, we leave you with these three final thoughts:

- Stop talking about improving marketing performance and accountability and start taking action.

- Even if you do not have all the data, start with what you have, define your data gaps and develop a plan to close these gaps.

- Stop reporting on activities. Using activities as a dashboard does not give your leadership team the information they need to make important strategic decisions.

Use the measures we have posited to develop your dashboard. Measures that matter are those that help your company make decisions and take action. When used this way, marketing metrics enable a firm to seize a competitive advantage.

\section{References}

1 Patterson, L. (2004) Measure What Matters: Reconnecting Marketing to Business Goals. VisionEdge Marketing, Glen Ellyn, Illinois.

2 Moving along the marketing accountability curve, Forrester research, Marketing Management Analytics, and the ANA, July 2005.

3 Kotler, P. (1999) Kotler on Marketing: How to Create, Win, and Dominate Markets. The Free Press, New York, NY.

4 CMO Reality Check, June 2005, CMO Magazine, www.cmomagazine.com. 